\title{
Novel binuclear copper(II) complexes of di-2-pyridyl ketone $N(4)$-methyl, N(4)-phenylthiosemicarbazone: Structural and spectral investigations
}

\author{
Varughese Philip ${ }^{\text {a }}$, V. Suni ${ }^{\text {a }}$, Maliyeckal R. Prathapachandra Kurup ${ }^{\text {a,* }}$, \\ Munirathinam Nethaji ${ }^{b}$ \\ a Department of Applied Chemistry, Cochin University of Science and Technology, Kochi 682 022, Kerala, India \\ ${ }^{\mathrm{b}}$ Department of Inorganic and Physical Chemistry, Indian Institute of Science, Bangalore 560 012, India
}

\begin{abstract}
Four binuclear complexes $[\mathrm{Cu}(\mathrm{dptsc}) \mathrm{Cl}]_{2} \cdot 3 \mathrm{H}_{2} \mathrm{O}(\mathbf{1}),[\mathrm{Cu}(\mathrm{dptsc}) \mathrm{Br}]_{2}(\mathbf{2}),\left[\mathrm{Cu}(\mathrm{dptsc})\left(\mu-\mathrm{N}_{3}\right)\right]_{2}(\mathbf{3})$ and $\left[\mathrm{Cu}(\mathrm{dptsc})\left(\mathrm{NO}_{3}\right)\right]_{2} \cdot \mathrm{H}_{2} \mathrm{O}(\mathbf{4})$ (where Hdptsc = di-2-pyridyl ketone $N(4)$-methyl, $N(4)$-phenylthiosemicarbazone) have been synthesized and physicochemically characterized. Each $\mathrm{Cu}(\mathrm{II})$ atom in the monomeric unit exists in a penta-coordinate environment. The molecular structures of $[\mathrm{Cu}(\mathrm{dptsc}) \mathrm{Br}]_{2}$ and $\left[\mathrm{Cu}(\mathrm{dptsc})\left(\mu-\mathrm{N}_{3}\right)\right]_{2}$ are resolved by single-crystal X-ray diffraction studies. Both the crystals are centrosymmetric dimers where each ligand unit coordinates through one of the pyridyl nitrogens, azomethine nitrogen and thiolate sulfur to $\mathrm{Cu}(\mathrm{II})$. $\mathrm{A}$ distorted square pyramidal geometry is observed around $\mathrm{Cu}(\mathrm{II})$ for both the complexes, where the $\mathrm{N}(2)$ nitrogen of the second ligand unit coordinates to the first $\mathrm{Cu}(\mathrm{II})$ center in compound $\mathbf{2}$ and $\mathrm{N}(6)$ nitrogen of the azido group bridges both the $\mathrm{Cu}(\mathrm{II})$ centers in compound 3. Spectral characterization corroborate the structural studies.
\end{abstract}

Keywords: Di-2-pyridyl ketone; Thiosemicarbazone; $\mathrm{Cu}(\mathrm{II})$ thiosemicarbazone complex; Crystal structure

\section{Introduction}

The ability of nitrogen and/or sulfur based donors to stabilize reduced and oxidized forms of copper(II) has sparked interest in their bioinorganic systems [1]. Thiosemicarbazones and their metal complexes are nowadays widely explored owing to their versatile biological activity and prospective use as drugs [2]. The potential anticancer, chemotherapeutic and superoxide dismutase-like activity of copper complexes with various thiosemicarbazones were first reported during 1950s [3,4]. Thereafter, a great variety of biological properties rang-

\footnotetext{
* Corresponding author. Tel.: +91 484 2575804; fax: +91 484 2577595.

E-mail address: mrp@cusat.ac.in (M.R. Prathapachandra Kurup).
}

ing from anticancer [5], antitumor [6], antibacterial [7], antifilarial [8] and antiviral [9] activities were explored with thiosemicarbazones, while the $\mathrm{Cu}$ (II) derivatives of bis(thiosemicarbazone) ligands served as radiopharmaceuticals [10] and revealed hypoxic selectivity [11]. For the past decade, we have been in constant pursuit of the synthesis, structural characterization and biological studies of a variety of substituted and unsubstituted thiosemicarbazones with different combinations of the aldehydes/ketones, with the aim to correlate their structural features with chelating ability and biological activity [12-17]. However, there are only few previous reports on di-2-pyridyl ketone thiosemicarbazones [18-22], and recently we have reported the synthesis and unique structural features of di-2-pyridyl ketone $N(4), N(4)$-(butane-1,4,diyl)thiosemicarbazone [23] and its $\mathrm{Ni}(\mathrm{II})$ 
complexes [24]. In this paper, we report the spectral characteristics of four copper(II) complexes derived from di-2-pyridyl ketone $N(4)$-methyl- $N(4)$-phenylthiosemicarbazone (Hdptsc) (Fig. 1). The crystal structures of two complexes formulated as $[\mathrm{Cu}(\mathrm{dptsc}) \mathrm{Br}]_{2}(2)$ and $\left[\mathrm{Cu}(\mathrm{dptsc})\left(\mu-\mathrm{N}_{3}\right)\right]_{2}(3)$ are also described.

\section{Experimental}

\subsection{Materials}

Di-2-pyridyl ketone (Fluka) was used as received. $\mathrm{Cu}$ $\mathrm{Cl}_{2} \cdot 2 \mathrm{H}_{2} \mathrm{O}, \mathrm{CuBr}_{2}, \mathrm{Cu}(\mathrm{OAc})_{2} \cdot \mathrm{H}_{2} \mathrm{O}, \mathrm{Cu}\left(\mathrm{NO}_{3}\right)_{2} \cdot 2.5-$ $\mathrm{H}_{2} \mathrm{O}$ and $\mathrm{NaN}_{3}$ were commercial products of higher grade (Merck) and solvents were purified according to standard procedures. Elemental analyses were carried out using a Heraeus Elemental Analyzer and the molar conductance measurements of the complexes were carried out in DMF solvent at $28 \pm 2{ }^{\circ} \mathrm{C}$ on a Century CC-601 digital conductivity meter with dip type cell and platinum electrode. Approximately $10^{-3} \mathrm{M}$ solutions were used. The magnetic susceptibility measurements were made using a simple Gouy balance at room temperature using mercury tetrathiocyanatocobaltate(II), $\mathrm{Hg}\left[\mathrm{Co}(\mathrm{NCS})_{4}\right]$ as calibrant. Infrared spectral measurements were done on a Shimadzu DR 8001 series FTIR instrument using $\mathrm{KBr}$ pellets for spectra in the region $4000-400 \mathrm{~cm}^{-1}$, and far IR spectra were recorded using polyethylene pellets in the $500-100 \mathrm{~cm}^{-1}$ region on a Nicolet Magna 550 FTIR instrument. An Ocean Optics SD 2000 Fiber Optic Spectrometer was used to measure solid-state reflectance spectra in the range 200-900 nm. ${ }^{1} \mathrm{H}$ NMR spectra were recorded using AMX $400 \mathrm{MHz}$ FT-NMR Spectrometer with $\mathrm{CDCl}_{3}$ as solvent and TMS as the internal standard. EPR spectral measurements were carried out on a Varian E-112 $\mathrm{X}$-band spectrometer using TCNE as standard.

\subsection{Synthesis of ligand}

The ligand, Hdptsc was synthesized as reported earlier [24]. A solution of di-2-pyridyl ketone (1.84 g,

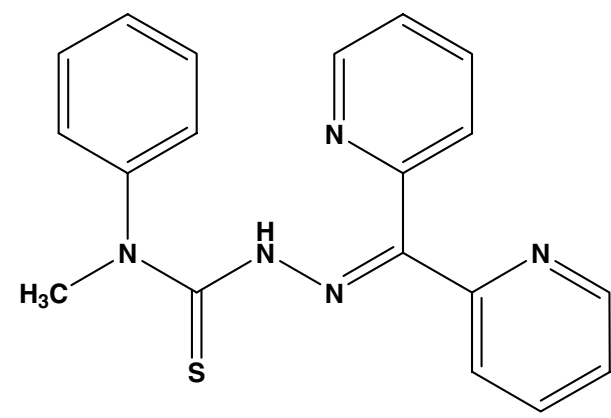

Fig. 1. Structure of Hdptsc.
$10 \mathrm{mmol})$ in $5 \mathrm{ml}$ methanol was treated with $N(4)$ methyl, $N(4)$-phenylthiosemicarbazide $(1.81 \mathrm{~g}, 10 \mathrm{mmol})$ in $25 \mathrm{ml}$ methanol and refluxed for $2 \mathrm{~h}$. On slow evaporation at room temperature, bright yellow crystals of Hdptsc separated out. These crystals were collected, washed with methanol and dried over $\mathrm{P}_{4} \mathrm{O}_{10}$ in vacuo.

\subsection{Synthesis of $\mathrm{Cu}($ dptsc $) \mathrm{Cl}_{2} \cdot 3 \mathrm{H}_{2} \mathrm{O}$ (1)}

Methanolic solutions of Hdptsc $(0.347 \mathrm{~g}, 1 \mathrm{mmol})$ and $\mathrm{CuCl}_{2} \cdot 2 \mathrm{H}_{2} \mathrm{O}(0.171 \mathrm{~g}, 1 \mathrm{mmol})$ were mixed and heated under reflux for $2 \mathrm{~h}$. Dark blue-green crystals of complex 1 were obtained, which were separated, washed with methanol followed by ether and dried over $\mathrm{P}_{4} \mathrm{O}_{10}$ in vacuo. Yield: $0.25 \mathrm{~g}(52 \%)$.

\subsection{Synthesis of $[\mathrm{Cu}(\mathrm{dptsc}) \mathrm{Br}]_{2}(2)$}

Hdptsc $(0.347 \mathrm{~g}, 1 \mathrm{mmol})$ was dissolved in methanol $(15 \mathrm{ml})$ and refluxed with a solution of $\mathrm{CuBr}_{2}(0.223 \mathrm{~g}$, $1 \mathrm{mmol}$ ) in 1:1 methanol-chloroform mixture. Blue crystals separated out, which were filtered, washed with methanol followed by ether and dried in vacuo. Colourless single crystals suitable for X-ray diffraction were grown by slow evaporation of a 1:1:1 solution of methanol, chloroform and dichloromethane of the complex. Yield: $0.175 \mathrm{~g}(33 \%)$.

\subsection{Synthesis of $\left[\mathrm{Cu}(\text { dptsc })\left(\mu-N_{3}\right)\right]_{2}(3)$}

$\mathrm{Cu}(\mathrm{OAc})_{2} \cdot \mathrm{H}_{2} \mathrm{O}(0.199 \mathrm{~g}, 1 \mathrm{mmol})$ dissolved in methanol $(15 \mathrm{ml})$ was added to Hdptsc $(0.347 \mathrm{~g}, 1 \mathrm{mmol})$ and refluxed. $\mathrm{NaN}_{3}(0.0651 \mathrm{~g}, 1 \mathrm{mmol})$ was then added to the solution and further refluxed for $3 \mathrm{~h}$. Dark blue crystals of 3 separated out, which were collected and dried in vacuo. Single crystals for X-ray diffraction were grown by slow evaporation of a 1:1:1 solution of methanol, chloroform and dichloromethane of the complex. Yield: $0.35 \mathrm{~g}(56 \%)$.

\subsection{Synthesis of $\left[\mathrm{Cu}(\text { dptsc })\left(\mathrm{NO}_{3}\right)\right]_{2} \cdot \mathrm{H}_{2} \mathrm{O}$ (4)}

A solution of $\mathrm{Cu}\left(\mathrm{NO}_{3}\right)_{2} \cdot 2.5 \mathrm{H}_{2} \mathrm{O}(0.233 \mathrm{~g}, 1 \mathrm{mmol})$ in a methanol-chloroform mixture $(20 \mathrm{ml}, \mathrm{v} / \mathrm{v})$ was added to Hdptsc $(0.347 \mathrm{~g}, 1 \mathrm{mmol})$ and refluxed for $2 \mathrm{~h}$. The resulting crystals were washed with methanol, followed by ether and dried in vacuo. Yield: $0.35 \mathrm{~g}$ $(65 \%)$.

\subsection{X-ray crystallography}

Single crystal X-ray diffraction measurements were carried out on a Bruker Smart Apex CCD diffractometer equipped with a fine-focused sealed tube. The unit cell parameters were determined and the data collections were performed using graphite-monochromated Mo Ka 
Table 1

Elemental analyses, colours and molar conductivities of the $\mathrm{Cu}(\mathrm{II})$ complexes

\begin{tabular}{|c|c|c|c|c|c|c|}
\hline \multirow[t]{2}{*}{ Compound } & \multirow[t]{2}{*}{ Colour } & \multicolumn{3}{|c|}{ Composition \% (Found/Calc.) } & \multirow[t]{2}{*}{$\lambda_{\mathrm{M}}^{\mathrm{a}}$} & \multirow[t]{2}{*}{$\mu_{\mathrm{eff}}^{\mathrm{b}}(\mathrm{BM})$} \\
\hline & & Carbon & Hydrogen & Nitrogen & & \\
\hline$[\mathrm{Cu}(\mathrm{dptsc}) \mathrm{Cl}]_{2} \cdot 3 \mathrm{H}_{2} \mathrm{O}(\mathbf{1})$ & Blue & $48.54(48.30)$ & $3.65(4.05)$ & $14.71(14.82)$ & 32 & 1.63 \\
\hline$[\mathrm{Cu}(\mathrm{dptsc}) \mathrm{Br}]_{2}(2)$ & Blue & $46.63(46.58)$ & $3.32(3.29)$ & $14.35(14.30)$ & 27 & 2.24 \\
\hline$\left[\mathrm{Cu}(\mathrm{dptsc})\left(\mu-\mathrm{N}_{3}\right)\right]_{2}(3)$ & Blue & $50.53(50.49)$ & $3.62(3.57)$ & $24.82(24.79)$ & 27 & 1.98 \\
\hline$\left[\mathrm{Cu}(\text { dptsc })\left(\mathrm{NO}_{3}\right)\right]_{2} \cdot \mathrm{H}_{2} \mathrm{O}(4)$ & Blue & $46.67(47.44)$ & $3.45(3.56)$ & $17.98(17.47)$ & 24 & 2.56 \\
\hline
\end{tabular}

${ }^{a}$ Molar conductivity, $10^{-3}$ M DMF at $298 \mathrm{~K}$.

b Magnetic susceptibility.

$(\lambda=0.71073 \AA$ ) radiation. Both the crystals were found to be monoclinic with a $P 2_{1} / c$ space group. Least square refinements of 17855 and 17083 reflections were done for compounds $\mathbf{2}$ and $\mathbf{3}$, respectively. The data collected were reduced using the SAINT program [25]. The trial structures were obtained by direct methods [26] using SHELXs-86, which revealed the position of all non-hydrogen atoms and refined by full-matrix least squares on $F^{2}$ (SHELXL-97) [27] and the graphic tool was DIAMOND for windows [28]. All non-hydrogen atoms were refined anisotropically, while the hydrogen atoms were treated with a mixture of independent and constrained refinements.

\section{Results and discussion}

\subsection{Synthesis of complexes}

Compounds 1, 2 and $\mathbf{4}$ were prepared by direct reaction between the ligand and the corresponding metal salts, while compound 3 was prepared by the displacement of the acetate in $\mathrm{Cu}(\mathrm{OAc})_{2} \cdot \mathrm{H}_{2} \mathrm{O}$ by the azide ion. The complexes are mostly blue or blue-green coloured, as expected with thiosemicarbazone coordination, resulting from the ligand to copper charge transfer bands [29]. Elemental analyses $(\mathrm{C}, \mathrm{H}, \mathrm{N})$ data (Table 1) of the complexes are consistent with the 1:1:1 ratio of metal:thiosemicarbazone:gegenion and also reveals that compounds $\mathbf{1}$ and $\mathbf{4}$ are hydrated. Conductivity measurements in DMF solution $\left(10^{-3} \mathrm{M}\right)$ indicate that all the complexes are non-electrolytes suggesting anionic coordination to the metal centre.

\subsection{Crystal structures of $[\mathrm{Cu}(\text { dptsc }) \mathrm{Br}]_{2}$ and $\left[\mathrm{Cu}(\operatorname{dptsc})\left(\mu-N_{3}\right)\right]_{2}$}

Structural studies of compound $\mathbf{2}$ reveal a threedimensional copper-thiosemicarbazone network consisting of two units of [Cudptsc] with a distorted square pyramidal geometry around $\mathrm{Cu}(\mathrm{II})$, with the basal plane

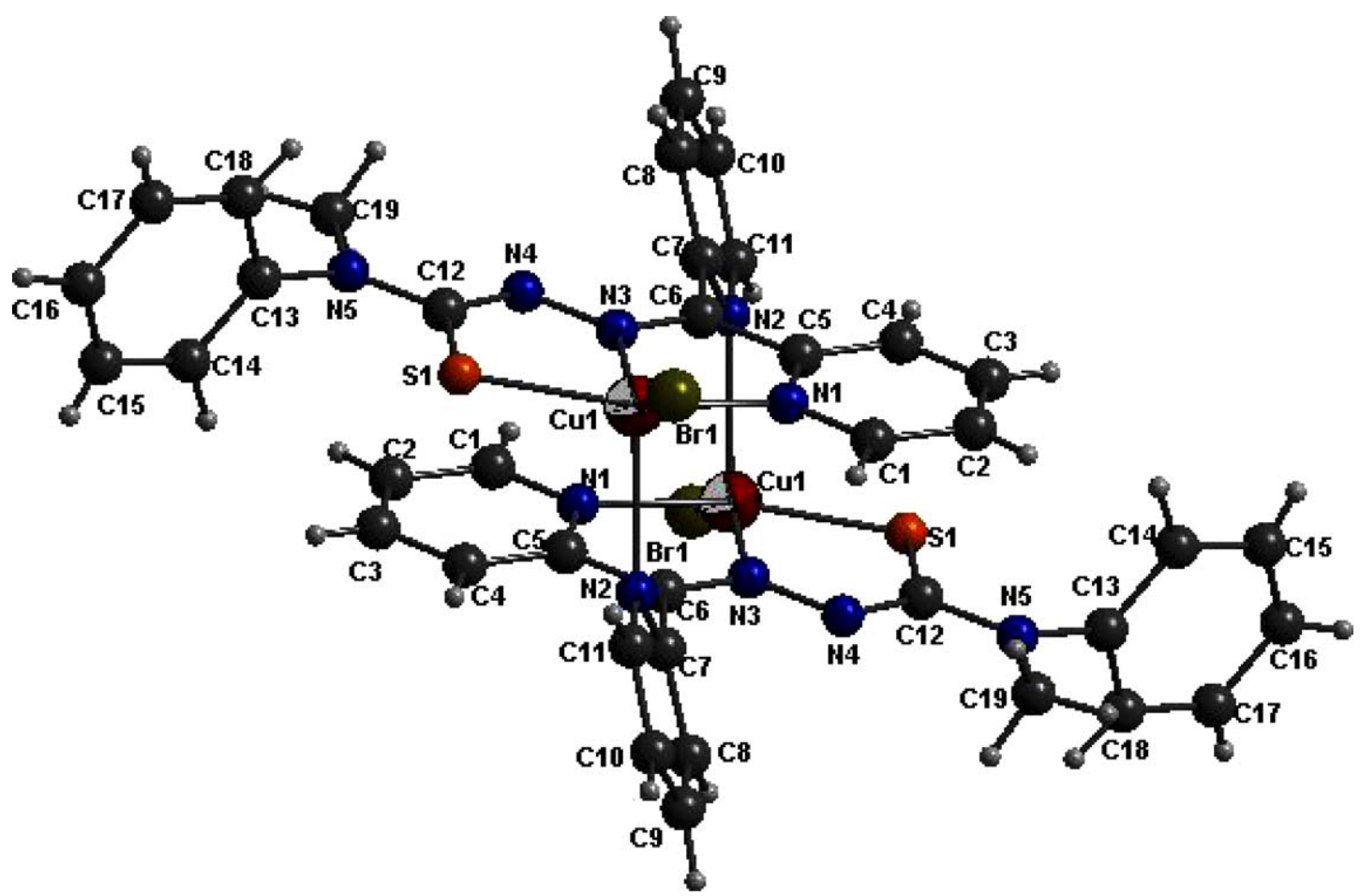

Fig. 2. Molecular structure of complex 2. 
consisting of one of the pyridyl nitrogens, azomethine nitrogen, thiolate sulfur and the bromine atom, while the pyridyl nitrogen of the second ligand unit occupies the apical position. A labelled representation of $\mathbf{2}$ is depicted in Fig. 2 along with the structural data refinements (Table 2) and selected bond distances and angles (Table 3). The bite angles $\mathrm{N}(1)-\mathrm{Cu}(1)-\mathrm{N}(3)$ $\left(80.05^{\circ}\right), \mathrm{Br}(1)-\mathrm{Cu}(1)-\mathrm{N}(1)\left(96.81^{\circ}\right), \mathrm{Br}(1)-\mathrm{Cu}(1)-\mathrm{S}(1)$ $\left(95.22^{\circ}\right)$ and $\mathrm{S}(1)-\mathrm{Cu}(1)-\mathrm{N}(3)\left(83.60^{\circ}\right)$ also support the distortion from square pyramidal geometry. The basal plane consisting of $\mathrm{N}(1), \mathrm{N}(3), \mathrm{Br}(1), \mathrm{S}(1)$ and $\mathrm{Cu}(1)$ shows a maximum mean deviation of $-0.3411 \AA$ at N3. The $\mathrm{Cu}$ (II) atom is deviated at a distance of $0.3002 \AA$ out of the mean plane towards the apical position. The thiosemicarbazone moiety comprising of $\mathrm{N}(5)$, $\mathrm{C}(12), \mathrm{S}(1), \mathrm{N}(4)$ and $\mathrm{N}(3)$ atoms and the pyridyl ring, $\mathrm{Cg}(3)$, make dihedral angles of $18.73^{\circ}$ and $18.58^{\circ}$, respectively, with the metal chelate $\mathrm{CuN}_{2} \mathrm{BrS}$ square plane. The loss of the proton bound to N(4) in Hdptsc produces a negative charge, which is delocalized on the thiosemicarbazone moiety. Delocalization of electron density over the entire thiosemicarbazone moiety is evidenced by the little marginal change in the $\mathrm{C}(6)$ $\mathrm{N}(3)$ and $\mathrm{N}(3)-\mathrm{N}(4)$ bond distances in 2, compared to that of the uncomplexed thiosemicarbazone [30]. The bond distance $\mathrm{S}(1)-\mathrm{C}(12)$ is longer and $\mathrm{C}(12)-\mathrm{N}(4)$ is shorter than the corresponding values in the free ligand, which support thiolate formation in the ligand on complexation [31].

The structural pattern of the discrete binuclear complex, $\left[\mathrm{Cu}(\mathrm{dptsc})\left(\mu-\mathrm{N}_{3}\right)\right]_{2}(3)$ is best viewed as two end-on $\mu_{1,1}$-azido bridged quasi-square pyramids. Each Hdptsc unit acts as a tridentate chelate, coordinating through one of the pyridyl nitrogens, azomethine nitrogen and the thiolate sulfur to a single $\mathrm{Cu}(\mathrm{II})$ center which is involved in a $\mu_{1,1}$-azido bridging to an identical coordination network, thus materializing a penta-coordinated environment (Fig. 3). The base of each distorted square pyramidal unit is occupied by $\mathrm{N}(1), \mathrm{N}(3), \mathrm{N}(6)$ and $\mathrm{S}(1)$ atoms, with the apical position occupied by the N(6) atom of the second azido group. Each azido ligand functions as an electron donor to the coordination network through an end-on azido bridging mode. The centrosymmetric nature of the structure is revealed by an inversion center with the two azido-bridged angles, $\mathrm{Cu}-\mathrm{N}-\mathrm{Cu}\left(92.94^{\circ}\right)$ and $\mathrm{N}-\mathrm{Cu}-\mathrm{N}\left(87.06^{\circ}\right)$, being the same in both the units. The intramolecular $\mathrm{Cu}-\mathrm{Cu}$ distance is found to be $3.303 \AA$ and the axial $\mathrm{Cu}(1)-\mathrm{N}(6)$

Table 2

Crystal data, data collection and structure refinement parameters for $[\mathrm{Cu}(\mathrm{dptsc}) \mathrm{Br}]_{2}$ and $\left[\mathrm{Cu}(\mathrm{dptsc})\left(\mathrm{N}_{3}\right)\right]_{2}$

\begin{tabular}{|c|c|c|}
\hline Parameters & {$[\mathrm{Cu}(\mathrm{dptsc}) \mathrm{Br}]_{2}$} & {$\left[\mathrm{Cu}(\mathrm{dptsc})\left(\mathrm{N}_{3}\right)\right]_{2}$} \\
\hline Empirical formula & $\mathrm{C}_{19} \mathrm{H}_{16} \mathrm{BrCuN}_{5} \mathrm{~S}$ & $\mathrm{C}_{19} \mathrm{H}_{16} \mathrm{CuN}_{8} \mathrm{~S}$ \\
\hline Formula weight (M) & 489.88 & 452.00 \\
\hline Temperature, $T(\mathrm{~K})$ & $293(2)$ & $293(2)$ \\
\hline Wavelength $(\mathrm{Mo} \mathrm{K} \alpha)(\AA)$ & 0.71073 & 0.71073 \\
\hline Crystal system & monoclinic & monoclinic \\
\hline Space group & $P 2_{1 / c}$ & $P 2_{1 / c}$ \\
\hline \multicolumn{3}{|l|}{ Lattice constants } \\
\hline$a(\AA)$ & $9.029(4)$ & $12.845(8)$ \\
\hline$b(\AA)$ & $17.279(8)$ & $12.512(7)$ \\
\hline$c(\AA)$ & $13.217(6)$ & $13.014(8)$ \\
\hline$\alpha\left({ }^{\circ}\right)$ & 90.00 & 90 \\
\hline$\beta\left({ }^{\circ}\right)$ & $97.228(8)$ & $107.753(10)$ \\
\hline$\gamma\left({ }^{\circ}\right)$ & 90.00 & 90.00 \\
\hline Volume, $V\left(\AA^{3}\right)$ & $2045.6(16)$ & $1992(2)$ \\
\hline$Z$ & 4 & 4 \\
\hline Calculated density, $\rho\left(\mathrm{Mg} \mathrm{m}^{-3}\right)$ & 1.591 & 1.507 \\
\hline Absorption coefficient, $\mu\left(\mathrm{mm}^{-1}\right)$ & 3.136 & 1.224 \\
\hline$F\left(\begin{array}{lll}0 & 0 & 0\end{array}\right)$ & 980 & 924 \\
\hline Crystal size (mm) & $0.41 \times 0.13 \times 0.11$ & $0.30 \times 0.12 \times 0.09$ \\
\hline$\theta$ Range for data collection & $2.36-27.98$ & $1.66-28.04$ \\
\hline Limiting indices & $-11 \leqslant h \leqslant 11,-22 \leqslant k \leqslant 22,-17 \leqslant l \leqslant 16$ & $-16 \leqslant h \leqslant 16,-16 \leqslant k \leqslant 16,-16 \leqslant l \leqslant 16$ \\
\hline Reflections collected & 17855 & 17083 \\
\hline Unique reflections & $4877\left[R_{\mathrm{int}}=0.0207\right]$ & $4682\left[R_{\mathrm{int}}=0.0265\right]$ \\
\hline Completeness to $\theta(\%)$ & $27.98(99.2)$ & $28.04(97.1)$ \\
\hline Maximum and minimum transmission & 0.7242 and 0.3596 & 0.8978 and 0.7102 \\
\hline Refinement method & full-matrix least-squares on $F^{2}$ & full-matrix least-squares on $F^{2}$ \\
\hline Data/restraints/parameters & $4877 / 0 / 296$ & $4682 / 0 / 326$ \\
\hline Goodness-of-fit on $F^{2}$ & 1.025 & 1.074 \\
\hline Final $R$ indices $[I>2 \sigma(I)]$ & $R_{1}=0.0431, w R_{2}=0.1202$ & $R_{1}=0.0375, w R_{2}=0.0859$ \\
\hline$R$ indices (all data) & $R_{1}=0.0558, w R_{2}=0.1296$ & $R_{1}=0.0490, w R_{2}=0.0908$ \\
\hline Largest difference peak and hole $\left(\mathrm{e} \AA^{-3}\right)$ & 1.455 and -0.538 & 0.418 and -0.218 \\
\hline
\end{tabular}


Table 3

Comparison of selected bond lengths $(\AA)$ and bond angles $\left(^{\circ}\right)$ of Hdptsc, $[\mathrm{Cu}(\mathrm{dptsc}) \mathrm{Br}]_{2}$ and $\left[\mathrm{Cu}(\mathrm{dptsc})\left(\mathrm{N}_{3}\right)\right]_{2}$

\begin{tabular}{|c|c|c|c|}
\hline & Hdptsc & {$[\mathrm{Cu}(\mathrm{dptsc}) \mathrm{Br}]_{2}$} & {$\left[\mathrm{Cu}(\mathrm{dptsc})\left(\mathrm{N}_{3}\right)\right]_{2}$} \\
\hline $\mathrm{S}(1)-\mathrm{C}(12)$ & 1.668 & 1.721 & 1.744 \\
\hline $\mathrm{N}(3)-\mathrm{C}(6)$ & 1.295 & 1.298 & 1.299 \\
\hline $\mathrm{N}(3)-\mathrm{N}(4)$ & 1.361 & 1.354 & 1.370 \\
\hline $\mathrm{N}(4)-\mathrm{C}(12)$ & 1.377 & 1.343 & 1.326 \\
\hline $\mathrm{N}(5)-\mathrm{C}(12)$ & 1.350 & 1.344 & 1.354 \\
\hline $\mathrm{Cu}(1)-\mathrm{S}(1)$ & & 2.2565 & 2.2603 \\
\hline $\mathrm{Cu}(1)-\mathrm{N}(1)$ & & 2.019 & 2.027 \\
\hline $\mathrm{Cu}(1)-\mathrm{N}(3)$ & & 1.979 & 1.964 \\
\hline $\mathrm{Cu}(1)-\mathrm{N}(2)$ & & 2.352 & \\
\hline $\mathrm{Cu}(1)-\mathrm{Br}(1)$ & & 2.4134 & \\
\hline $\mathrm{Cu}(1)-\mathrm{N}(6)$ & & & 1.9561 \\
\hline $\mathrm{Cu}(1)-\mathrm{N}(6) \mathrm{a}$ & & & 2.5628 \\
\hline $\mathrm{C}(6)-\mathrm{N}(3)-\mathrm{N}(4)$ & 120.87 & 118.9 & 120.36 \\
\hline $\mathrm{N}(3)-\mathrm{N}(4)-\mathrm{C}(12)$ & 118.72 & 111.1 & 111.68 \\
\hline $\mathrm{N}(5)-\mathrm{C}(12)-\mathrm{N}(4)$ & 113.74 & 115.6 & 115.02 \\
\hline $\mathrm{N}(5)-\mathrm{C}(12)-\mathrm{S}(1)$ & 123.48 & 118.9 & 119.09 \\
\hline $\mathrm{N}(4)-\mathrm{C}(12)-\mathrm{S}(1)$ & 122.77 & 125.4 & 124.89 \\
\hline $\mathrm{N}(1)-\mathrm{Cu}(1)-\mathrm{N}(3)$ & & 80.05 & 80.56 \\
\hline $\mathrm{S}(1)-\mathrm{Cu}(1)-\mathrm{N}(1)$ & & 163.28 & 160.88 \\
\hline $\mathrm{S}(1)-\mathrm{Cu}(1)-\mathrm{N}(3)$ & & 83.60 & 84.95 \\
\hline $\mathrm{S}(1)-\mathrm{Cu}(1)-\mathrm{N}(2)$ & & 100.88 & \\
\hline $\mathrm{N}(2)-\mathrm{Cu}(1)-\mathrm{N}(1)$ & & 89.00 & \\
\hline $\mathrm{N}(2)-\mathrm{Cu}(1)-\mathrm{N}(3)$ & & 113.93 & \\
\hline $\mathrm{Br}(1)-\mathrm{Cu}(1)-\mathrm{S}(1)$ & & 95.22 & \\
\hline $\mathrm{Br}(1)-\mathrm{Cu}(1)-\mathrm{N}(1)$ & & 96.81 & \\
\hline $\mathrm{Br}(1)-\mathrm{Cu}(1)-\mathrm{N}(2)$ & & 97.60 & \\
\hline $\mathrm{Br}(1)-\mathrm{Cu}(1)-\mathrm{N}(3)$ & & 148.15 & \\
\hline $\mathrm{S}(1)-\mathrm{Cu}(1)-\mathrm{N}(6)$ & & & 100.81 \\
\hline $\mathrm{S}(1)-\mathrm{Cu}(1)-\mathrm{N}(7)$ & & & 81.74 \\
\hline $\mathrm{S}(1)-\mathrm{Cu}(1)-\mathrm{N}(6) \mathrm{a}$ & & & 104.53 \\
\hline $\mathrm{N}(1)-\mathrm{Cu}(1)-\mathrm{N}(6)$ & & & 94.28 \\
\hline $\mathrm{N}(1)-\mathrm{Cu}(1)-\mathrm{N}(7)$ & & & 112.12 \\
\hline $\mathrm{N}(1)-\mathrm{Cu}(1)-\mathrm{N}(6) \mathrm{a}$ & & & 87.77 \\
\hline $\mathrm{N}(3)-\mathrm{Cu}(1)-\mathrm{N}(6)$ & & & 173.80 \\
\hline $\mathrm{N}(3)-\mathrm{Cu}(1)-\mathrm{N}(7)$ & & & 166.63 \\
\hline $\mathrm{N}(3)-\mathrm{Cu}(1)-\mathrm{N}(6) \mathrm{a}$ & & & 89.29 \\
\hline $\mathrm{N}(6)-\mathrm{Cu}(1)-\mathrm{N}(7)$ & & & 19.40 \\
\hline $\mathrm{N}(6)-\mathrm{Cu}(1)-\mathrm{N}(6) \mathrm{a}$ & & & 87.06 \\
\hline $\mathrm{N}(7)-\mathrm{Cu}(1)-\mathrm{N}(6) \mathrm{a}$ & & & 95.25 \\
\hline $\mathrm{Cu}(1)-\mathrm{N}(6)-\mathrm{Cu}(1) \mathrm{a}$ & & & 92.94 \\
\hline
\end{tabular}

distance is found to be $2.5628 \AA$. The nitrogen atoms $\mathrm{N}(3)$ and $\mathrm{N}(6)$ are closer to the $\mathrm{Cu}(\mathrm{II})$ center with bond distances $\mathrm{Cu}(1)-\mathrm{N}(3) \quad(1.964 \AA)$ and $\mathrm{Cu}(1)-\mathrm{N}(6)$ $(1.956 \AA)$ compared to $\mathrm{Cu}(1)-\mathrm{N}(1) \quad(2.027 \AA)$ and $\mathrm{Cu}(1)-\mathrm{S}(1) \quad(2.2603 \AA)$. A maximum deviation of $0.1649 \AA$ at $\mathrm{N}(1)$ is revealed at the base of the square pyramid with the central $\mathrm{Cu}(\mathrm{II})$ atom positioned $0.0689 \AA$ above the mean plane. The pyridyl ring $\mathrm{Cg}(1)$ is less deviated from the basal plane (the dihedral angle between the two least square planes is $3.00^{\circ}$ ), when compared to the thiosemicarbazone moiety, which deviates more, at a dihedral angle of $13.51^{\circ}$ from the basal $\mathrm{CuN}_{3} \mathrm{~S}$ plane. The dimer is located on an inversion centre and the bridging $\mathrm{Cu}_{2} \mathrm{~N}_{2}$ network is perfectly planar. Similar to 2 above, the $\mathrm{C}(6)-\mathrm{N}(3)$ and $\mathrm{N}(3)-\mathrm{N}(4)$ bond distances in 3 reveal extensive delocalization over the entire binuclear coordination framework.

The diverse $\pi-\pi$ stacking, $\mathrm{C}-\mathrm{H}---\pi$ and ring-metal interactions give rise to polymeric chains in the unit cells of 2 and 3 (Figs. 4 and 5). The shortest $\pi-\pi$ interactions are perceived at $3.3631 \AA$ for $\mathrm{Cg}(2)-\mathrm{Cg}(2)^{\mathrm{i}}[\mathrm{i}=1-x$, $1-y, 1-z]$ in 2 . Ring-metal interactions $\operatorname{Cg}(2)---$ $\mathrm{Cu}(1)^{\mathrm{iii}}[$ iii $=x, 1 / 2-y, 1 / 2+z]$ are observed in 3 at a distance of $3.774 \AA$. Two $\mathrm{C}-\mathrm{H}---\pi$ interactions each are shown in the unit cells of $\mathbf{2}$ and $\mathbf{3}$. They are $\mathrm{C}(8)$ $\mathrm{H}(8)--\mathrm{Cg}(1)^{\mathrm{iv}} \quad\left[\mathrm{d}_{H--C g}=3.0853 \AA\right.$ A $; \quad$ iv $\left.=-1+x, y, z\right]$ and $\mathrm{C}(10)-\mathrm{H}(10)--\mathrm{Cg}(5)^{\mathrm{v}} \quad\left[\mathrm{d}_{H-\ldots C g}=2.6471 \AA ; \quad \mathrm{v}=\right.$ $-1+x, 1 / 2-y,-1 / 2+z]$ for 2 and $\mathrm{C}(10)-\mathrm{H}(10)--$ $\mathrm{Cg}(3)^{\mathrm{vi}}\left[\mathrm{d}_{H-\ldots C g}=2.9888 \AA\right.$; vi $\left.=1-x,-y, 1-z\right]$ and $\mathrm{C}(15)-\mathrm{H}(15)--\mathrm{Cg}(2)^{\mathrm{vii}}\left[\mathrm{d}_{H--C}=2.9537 \AA ; \mathrm{v}=1-x\right.$, $-1 / 2+y, 1 / 2-z]$ for compound 3 .

\subsection{Spectrochemical studies}

The $v_{\mathrm{a}}(\mathrm{N}-\mathrm{H})$ vibrations of the imino group are observed at ca. $3428 \mathrm{~cm}^{-1}$ in the IR spectrum of Hdptsc. In the ${ }^{1} \mathrm{H}$ NMR spectrum, the $\mathrm{N}(4) \mathrm{H}$ resonance, at a downfield value of $14.68 \mathrm{ppm}$, is consistent with the intramolecular $\mathrm{N}(4)-\mathrm{H}---\mathrm{N}(2)$ hydrogen bonding revealed by its crystal structure [30]. A strong band at $1580 \mathrm{~cm}^{-1}$ in the IR spectrum of Hdptsc corresponds to $v$ (N3-C6) stretching, which suffers a positive shift on complexation due to a change in bond order [31,32] (Table 4). The absence of a $v(\mathrm{~S}-\mathrm{H})$ band around $2565 \mathrm{~cm}^{-1}$ supports the predominant thione form of the ligand in the solid state, while the lack of an $(\mathrm{N}-\mathrm{H})$ stretching in the spectra of the complexes endorses the ligand coordination to $\mathrm{Cu}(\mathrm{II})$ ion in the deprotonated thiolate form. A medium band around $644 \mathrm{~cm}^{-1}$ indicates out-of-plane pyridyl ring vibrations $\rho$ (py) of Hdptsc, which suffers a positive shift in all complexes. The IR bands observed at 1360 and $793 \mathrm{~cm}^{-1}$ in the ligand have significant contributions from $\mathrm{C}=\mathrm{S}$ stretching and bending vibrations, and are shifted to lower wavenumbers on complexation [33]. Solid state reflectance spectrum of the ligand shows an absorption maximum in the region $37000 \mathrm{~cm}^{-1}$ attributed to intra-ligand $\pi^{*} \leftarrow \pi$ transitions of the pyridyl ring and imine function of the thiosemicarbazone moiety (Table 5). The peaks at ca. 27000 and $30030 \mathrm{~cm}^{-1}$ indicate $\pi^{*} \leftarrow \mathrm{n}$ transitions of the thioamide function, which are shifted to higher energy values upon complexation. As expected, the $\mathrm{Cu}(\mathrm{II}) \leftarrow \mathrm{S}$ charge transfer transitions [34] are observed at ca. $23000 \mathrm{~cm}^{-1}$. For all the compounds, the peaks observed at ca. 17000 and $14000 \mathrm{~cm}^{-1}$ are assigned to $\mathrm{d}_{x z}$, $\mathrm{d}_{y z} \leftarrow \mathrm{d}_{x^{2}-y^{2}}$ and $\mathrm{d}_{z}^{2} \leftarrow \mathrm{d}_{x^{2}-y^{2}}$ transitions in an elongated square based pyramidal geometry [35,36]. Magnetic moment values for the bromo (2) and nitrato (4) complexes are greater than the spin only value for a dimeric system, since a larger $\mathrm{Cu}-\mathrm{Cu}$ distance, revealed by the crystal structure in $\mathbf{2}$, render the electron spins parallel resulting 


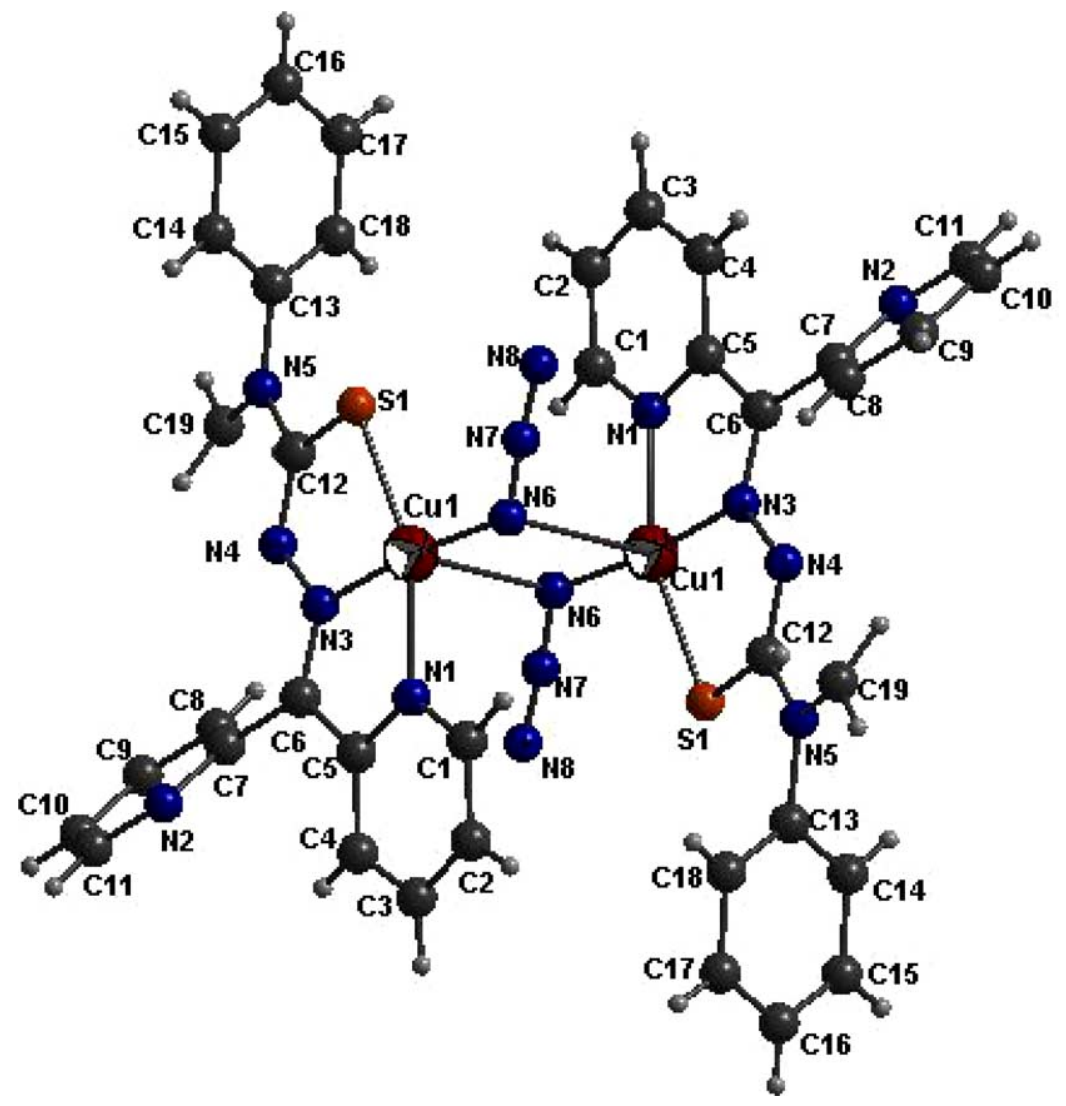

Fig. 3. Molecular structure of complex 3.

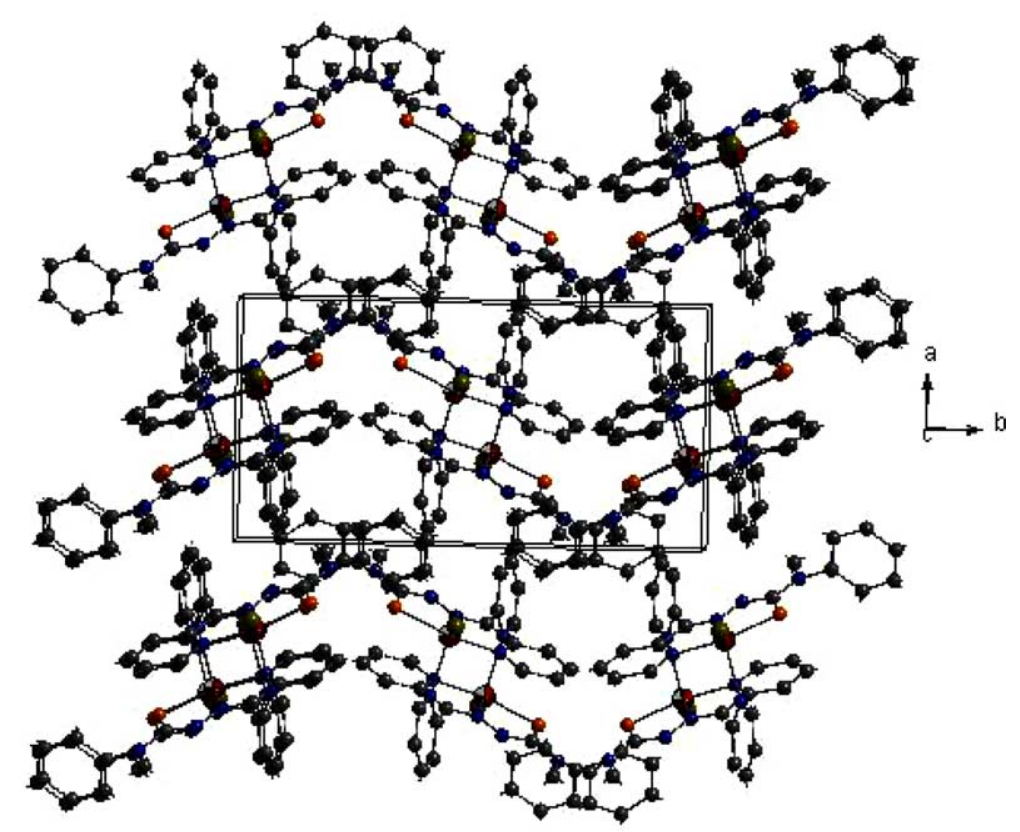

Fig. 4. Molecular packing diagram of 2 viewed down the ' $c$ ' axis.

in a high magnetic moment. The azido (3) and the chloro complex (1) show magnetic moment values close to the spin only value per copper for a dimer, suggesting the ab- sence of spin-orbit coupling and anti-ferromagnetic interactions. A medium band at $245 \mathrm{~cm}^{-1}$ in the IR spectrum of $\mathbf{2}$ is indicative of the coordinated bromine. 


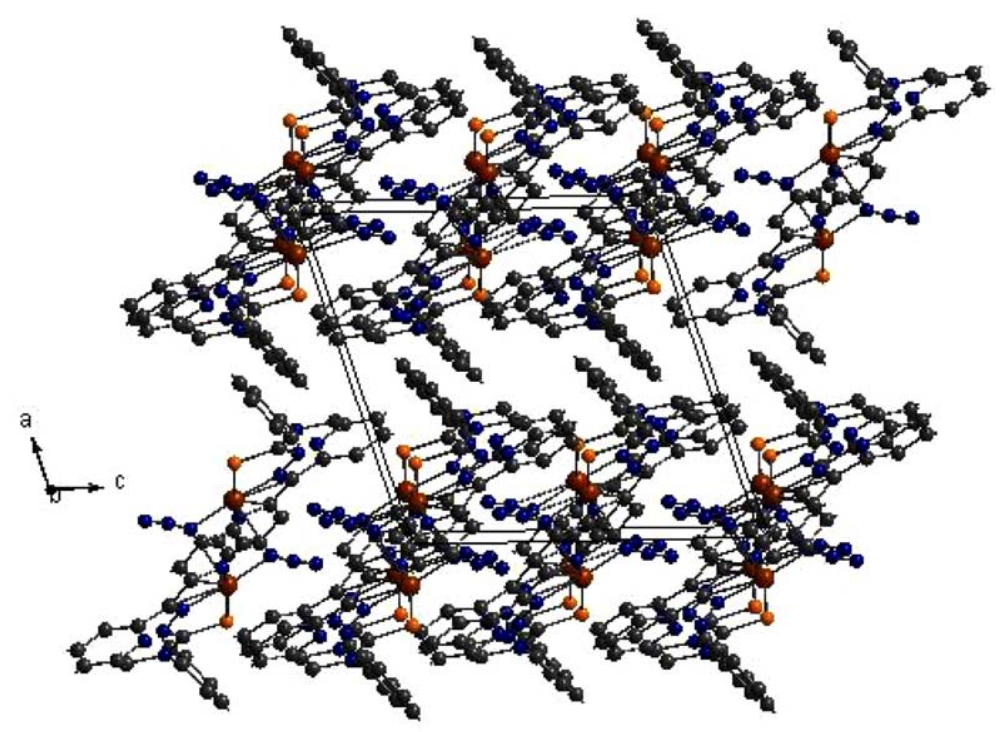

Fig. 5. Molecular packing diagram of $\mathbf{3}$ viewed down the ' $b$ ' axis.

Table 4

Selected IR bands $\left(\mathrm{cm}^{-1}\right)$ with tentative assignments for the complexes

\begin{tabular}{|c|c|c|c|c|c|c|c|c|c|}
\hline Compound & $v(\mathrm{C}=\mathrm{N})+v(\mathrm{~N}=\mathrm{C})$ & $v(\mathrm{~N}-\mathrm{N})$ & $v(\mathrm{C}=\mathrm{S})$ & $\delta(\mathrm{C}=\mathrm{S})$ & $\delta$ (o.p) & $v(\mathrm{Cu}-\mathrm{N})$ & $v(\mathrm{Cu}-\mathrm{S})$ & $v(\mathrm{Cu}-\mathrm{N})$ py & $v\left(\mathrm{Cu}-\mathrm{X}^{\#}\right)$ \\
\hline Hdptsc & $1580 \mathrm{~s}$ & $1051 \mathrm{w}$ & $1360 \mathrm{~s}$ & $793 \mathrm{~m}$ & $644 \mathrm{~m}$ & & & & \\
\hline$[\mathrm{Cu}(\mathrm{dptsc}) \mathrm{Cl}]_{2} \cdot 3 \mathrm{H}_{2} \mathrm{O}(\mathbf{1})$ & $1592 \mathrm{~m}$ & $1004 \mathrm{w}$ & $1305 \mathrm{~m}$ & $781 \mathrm{w}$ & $683 \mathrm{w}$ & $419 \mathrm{~s}$ & $325 \mathrm{~s}$ & $353 \mathrm{~m}$ & $303 \mathrm{~m}$ \\
\hline$[\mathrm{Cu}(\mathrm{dptsc}) \mathrm{Br}]_{2}(\mathbf{2})$ & $1590 \mathrm{w}$ & $1002 \mathrm{w}$ & $1306 \mathrm{~m}$ & $781 \mathrm{~m}$ & $692 \mathrm{~m}$ & $419 \mathrm{~s}$ & $328 \mathrm{~m}$ & $350 \mathrm{~m}$ & $245 \mathrm{~m}$ \\
\hline$\left[\mathrm{Cu}(\mathrm{dptsc})\left(\mu-\mathrm{N}_{3}\right)\right]_{2}(3)$ & $1594 \mathrm{~m}$ & $1011 \mathrm{~m}$ & $1310 \mathrm{sh}$ & $778 \mathrm{w}$ & $699 \mathrm{~m}$ & $444 \mathrm{~s}$ & $332 \mathrm{sh}$ & $351 \mathrm{~m}$ & $315 \mathrm{~m}$ \\
\hline$\left[\mathrm{Cu}(\mathrm{dptsc})\left(\mathrm{NO}_{3}\right)\right]_{2} \cdot \mathrm{H}_{2} \mathrm{O}(\mathbf{4})$ & $1592 \mathrm{w}$ & $1005 \mathrm{~m}$ & $1308 \mathrm{~m}$ & $775 \mathrm{~m}$ & $692 \mathrm{~m}$ & $416 \mathrm{~s}$ & $325 \mathrm{~m}$ & $355 \mathrm{~m}$ & $444 \mathrm{w}$ \\
\hline
\end{tabular}

Table 5

Electronic spectral data $\left(\mathrm{cm}^{-1}\right)$ of Hdptsc and the complexes

\begin{tabular}{|c|c|c|c|c|}
\hline Compound & $d-d$ & $\mathrm{C} \mathrm{T}$ & $\pi^{*} \leftarrow \mathrm{n}$ & $\pi^{*} \leftarrow \pi$ \\
\hline Hdptsc & & & $\begin{array}{l}26882 \mathrm{~s} \\
30030 \mathrm{sh}\end{array}$ & $\begin{array}{l}37543 \mathrm{~s}, \\
32787 \mathrm{sh}\end{array}$ \\
\hline$[\mathrm{Cu}(\mathrm{dptsc}) \mathrm{Cl}]_{2} \cdot 3 \mathrm{H}_{2} \mathrm{O}(\mathbf{1})$ & $\begin{array}{l}17636 \mathrm{sh} \\
14084 \mathrm{sh}\end{array}$ & $\begin{array}{l}24814 \mathrm{sh} \\
23201 \mathrm{~s}\end{array}$ & $\begin{array}{l}32154 \mathrm{~s} \\
30395 \mathrm{~b}\end{array}$ & $37313 \mathrm{~s}$ \\
\hline$[\mathrm{Cu}(\mathrm{dptsc}) \mathrm{Br}]_{2}(\mathbf{2})$ & $\begin{array}{l}17699 \mathrm{sh} \\
14556 \mathrm{sh}\end{array}$ & $\begin{array}{l}28169 \mathrm{sh} \\
23310 \mathrm{sh} \\
22831 \mathrm{~s}, \mathrm{~b}\end{array}$ & $\begin{array}{l}32467 \mathrm{~s} \\
31648 \mathrm{sh}\end{array}$ & $37453 \mathrm{~s}$ \\
\hline$\left[\mathrm{Cu}(\mathrm{dptsc})\left(\mu-\mathrm{N}_{3}\right)\right]_{2}(\mathbf{3})$ & $\begin{array}{l}17211 \mathrm{sh}, \\
144450 \mathrm{sh}\end{array}$ & $\begin{array}{l}26882 \mathrm{sh}, \\
22676 \mathrm{~s}\end{array}$ & $\begin{array}{l}32573 \mathrm{sh}, \\
30864 \mathrm{sh}\end{array}$ & \\
\hline$\left[\mathrm{Cu}(\mathrm{dptsc})\left(\mathrm{NO}_{3}\right)\right]_{2} \cdot \mathrm{H}_{2} \mathrm{O}(4)$ & $\begin{array}{l}17007 \mathrm{sh} \\
14104 \mathrm{sh}\end{array}$ & $\begin{array}{l}23095 \mathrm{~s}, \mathrm{~b} \\
16949 \mathrm{sh}\end{array}$ & $30487 \mathrm{~s}, \mathrm{~b}$ & $38314 \mathrm{sh}$ \\
\hline
\end{tabular}

Compound 3 exhibits strong bands at 2041 and $1310 \mathrm{~cm}^{-1}$ corresponding to the $v_{\mathrm{a}}$ and $v_{\mathrm{s}}$ of the coordinating azido group [37]. The prominent bands at $699 \mathrm{~cm}^{-1}$ and a weak band at $444 \mathrm{~cm}^{-1}$, assigned to $\delta(\mathrm{NNN})$ and $v(\mathrm{Cu}-\mathrm{N})$, suggest a non-linear $\mathrm{Cu}-\mathrm{N}-\mathrm{N}-$ $\mathrm{N}$ bond [34]. Bands corresponding to $v_{1}, v_{2}, v_{4}$ at 1010 , 1284 and $1385 \mathrm{~cm}^{-1}$, respectively, are observed in 4 whereas a $v_{1}+v_{4}$ combination band at ca. $1750 \mathrm{~cm}^{-1}$ indicates monocoordinated nitrato group [37]. Magnetic moment measurement of $\mathbf{4}$ supports its potential dimeric disposition where the magnetic susceptibility value is found to be higher than that of a coupled $\mathrm{Cu}$ (II) ion pair, which is presumed with the association of small amounts of paramagnetic impurities in the compounds [38]. 


\subsection{Electron paramagnetic resonance spectra}

EPR spectra of the samples with $100-\mathrm{kHz}$ field modulation at room temperature were recorded in the $\mathrm{X}$-band. An isotropic spectrum with a broad signal is obtained for $\mathbf{3}$ and the remaining complexes gave axial spectra in the solid state at room temperature. The copper(II) ion, with a $\mathrm{d}^{9}$ configuration, has an effective spin of $S=1 / 2$ and is associated with a spin angular momentum $m_{\mathrm{s}}= \pm 1 / 2$, leading to a doubly degenerate spin state in the absence of a magnetic field. In a magnetic field the degeneracy is lifted between these states and the energy difference between them is given by $E=h v=g \beta H$, where $h$ is Planck's constant, $v$ is the frequency, $g$ is the Lande's splitting factor (equal to 2.0023 for a free electron), $\beta$ is the Bohr magneton and $H$ is the magnetic field. For the case of a $3 \mathrm{~d}^{9}$ copper(II) ion, the appropriate spin Hamiltonian assuming a $B_{1 \mathrm{~g}}$ ground state [36] is given by:

$\hat{H}=\beta\left[g_{\|} H_{z} S_{z}+g_{\perp}\left(H_{x} S_{x}+H_{y} S_{y}\right)\right]+A_{\|} I_{z} S_{z}+A_{\perp}\left(I_{x} S_{x}+I_{y} S_{y}\right)$

The EPR spectra of the compounds $\mathbf{1 ,} \mathbf{2}$ and $\mathbf{4}$ in the polycrystalline state at $298 \mathrm{~K}$ show typical axial spectra with slightly different $g_{\|}$and $g_{\perp}$ features. The variations in $g$ values indicate that the geometry of the compound is affected by the nature of the coordinating gegenions (Table 6). The spectrum of compound 3 in the polycrystalline state $(298 \mathrm{~K})$ shows a broad signal indicating only one $g$ value, 2.0638 , due to dipolar broadening and enhanced spin lattice relaxation.

The geometric parameter $G$ calculated as $G=$ $\left(g_{\|}-2.003\right) /\left(g_{\perp}-2.003\right)$ is a measure of the exchange interaction between copper centers in the polycrystalline compound. It is perceived that, if $G>4$, the exchange interaction is negligible and vice versa in the complexes. All complexes with $g_{\|}>g_{\perp}>2.003$ and $G$ values falling within the range of 2-4 are consistent with a $\mathrm{d}_{x^{2}-y^{2}}$ ground state in a square planar or square pyramidal geometry. The $g$ values are found to be lower than those reported for copper(II) complexes prepared from a substituted 2-benzoylpyridine thiosemicarbazone [39], indicating a stronger metal-ligand bonding. Absence of half field signals for the compounds reinforces the assumption of very weak super exchange interactions.
The solution spectra of complexes $\mathbf{1}$ and $\mathbf{4}$ were recorded in DMF at $298 \mathrm{~K}$. They are isotropic in nature with well-resolved four hyperfine lines. The hyperfine splitting is due to the interaction of the electron spin with the copper nuclear spin $\left({ }^{65} \mathrm{Cu}, I=3 / 2\right)$. There are indications of nitrogen superhyperfine splitting in the high field component in some spectra. The $A_{\text {iso }}$ and $g_{\text {iso }}$ values show variations in $\mathbf{1}$ and $\mathbf{4}$, their values indicating dissimilarity in bonding in the complexes.

The spectra of complexes $\mathbf{1 , 3}$ and $\mathbf{4}$ in DMF at $77 \mathrm{~K}$ show rhombic features with three $g$ values $g_{1}, g_{2}$, and $g_{3}$ where $g_{3}>g_{2}>g_{1}$. It is observed that the $g$ values for complexes in the solid state at $298 \mathrm{~K}$ and in DMF at $77 \mathrm{~K}$ are not much different from each other, hence the geometry around the copper(II) ion is unaffected on cooling the solution to liquid nitrogen temperature. In the low field region, the chloro and nitrato complexes show six hyperfine lines that are moderately resolved and perpendicular features overlapping with seventh one suggesting a dimeric state with two copper centers. The $g_{3}$ values of the complexes are less than 2.3 and they assign considerable covalent character to the $\mathrm{M}-\mathrm{L}$ bonds [40]. For the compounds $\mathbf{1}, \mathbf{3}$ and $\mathbf{4}$, the lowest $g$ value $\left(g_{1}\right)$ is less than 2.04 indicating a compressed rhombic symmetry with all axes aligned parallel and is consistent with distorted trigonal bipyramidal stereochemistry or a compressed axial symmetry or rhombic symmetry with slight misalignment of the axes. In the spectra with $g_{3}>g_{2}>g_{1}$, rhombic spectral values $R=\left(g_{2}-g_{1}\right) /\left(g_{3}-g_{2}\right)$ may be significant. If $R>1$, a predominant $\mathrm{d}_{z^{2}}$ ground state is present. If $R<1$, a predominant $\mathrm{d}_{x^{2}-y^{2}}$ ground state is present and when $R=1$, then the ground state is approximately an equal mixture of $\mathrm{d}_{z^{2}}$ and $\mathrm{d}_{x^{2}-y^{2}}$, the structure is intermediate between square planar and trigonal bipyramidal geometries. All the present complexes have values $R<1$ suggesting a distorted square based pyramidal geometry with a $\mathrm{d}_{x^{2}-y^{2}}$ ground state. These observations are consistent with $g$ values of the corresponding complexes in the polycrystalline state at $298 \mathrm{~K}$ and further supports the distorted square pyramidal geometry around copper(II) ion in these complexes.

Spin Hamiltonian parameters are calculated from the frozen state EPR and electronic spectra (Table 7). The

Table 6

EPR spectral assignments (experimental) for the copper(II) complexes

\begin{tabular}{|c|c|c|c|c|c|c|c|c|c|c|c|c|}
\hline \multirow[t]{2}{*}{ Compound } & \multicolumn{3}{|c|}{ Solid (298 K) } & \multicolumn{3}{|c|}{$\operatorname{DMF}(298 \mathrm{~K})$} & \multicolumn{6}{|c|}{ DMF $(77 \mathrm{~K})$} \\
\hline & $g \|$ & $g_{\text {iso }}$ & $g_{\perp}$ & $g_{\text {iso }}$ & $A_{\text {iso }}$ & $A_{N}$ & $g_{3} / g \|$ & $g_{2}$ & $g_{1} / g_{\perp}$ & $g_{\text {av }}$ & $A \|^{\mathrm{a}}$ & $A_{\perp}(N)^{\mathrm{a}}$ \\
\hline$\overline{[\mathrm{Cu}(\mathrm{dptsc}) \mathrm{Cl}]_{2} \cdot 3 \mathrm{H}_{2} \mathrm{O}(\mathbf{1})}$ & 2.1422 & & 2.0576 & 2.0446 & 43.33 & 15 & 2.2224 & 2.0597 & 1.9808 & 2.0876 & 63.33 & 11.66 \\
\hline$[\mathrm{Cu}(\mathrm{dptsc}) \mathrm{Br}]_{2}(\mathbf{2})$ & 2.1349 & & 2.0602 & & & & 2.1423 & & 2.0612 & 2.0882 & & \\
\hline$\left[\mathrm{Cu}(\mathrm{dptsc})\left(\mu-\mathrm{N}_{3}\right)\right]_{2}(3)$ & & 2.0638 & & & & & 2.1961 & 2.0631 & 1.9868 & 2.0820 & 175 & 22 \\
\hline$\left[\mathrm{Cu}(\text { dptsc })\left(\mathrm{NO}_{3}\right)\right]_{2} \cdot \mathrm{H}_{2} \mathrm{O}(4)$ & 2.1484 & & 2.0384 & 2.1047 & 48.33 & 20 & 2.1816 & 2.0341 & 1.9723 & 2.0627 & & \\
\hline
\end{tabular}

${ }^{\text {a }}$ A values in $10^{-4} \mathrm{~cm}^{-1}$. 
Table 7

Spin Hamiltonian and orbital reduction parameters of the complexes 1 and 4

\begin{tabular}{lll}
\hline Compound & {$\left[\mathrm{Cu}(\mathrm{dptsc}) \mathrm{Cl}_{2} \cdot 3 \mathrm{H}_{2} \mathrm{O}(\mathbf{1})\right.$} & {$\left[\mathrm{Cu}(\mathrm{dptsc})\left(\mathrm{NO}_{3}\right)\right]_{2} \cdot \mathrm{H}_{2} \mathrm{O}(\mathbf{4})$} \\
\hline$g_{\| / g z z}\left(g_{3}\right)$ & 2.2224 & 2.1816 \\
$g_{y y}\left(g_{2}\right)$ & 2.0597 & 2.0341 \\
$g_{x x}\left(g_{1)}\right.$ & 1.9808 & 1.9723 \\
$g_{\text {av }}(77 k)$ & 2.0876 & 2.0627 \\
$g_{\text {av }}($ solid $)$ & 2.0858 & 2.0750 \\
$R^{\mathrm{a}}$ & 0.404 & 0.98 \\
$K_{\|}$ & 0.6686 & 0.6357 \\
$K_{\perp}$ & 0.6534 & 0.6030 \\
\hline${ }^{\mathrm{a}} R=\left(g_{2}-g_{1}\right) /\left(g_{3}-g_{2}\right)$.
\end{tabular}

orbital reduction factors were estimated using the following expressions [41].

$K_{\|}^{2}=\left(g_{\|}-2.0023\right) \Delta E\left(\mathrm{~d}_{x y}-\mathrm{d}_{x^{2}-y^{2}}\right) / 8 \lambda_{0}$,

$K_{\perp}^{2}=\left(g_{\perp}-2.0023\right) \Delta E\left(\mathrm{~d}_{x z, y z}-\mathrm{d}_{x^{2}-y^{2}}\right) / 2 \lambda_{0}$,

where $\lambda_{0}$ is the spin-orbit coupling constant and has a value of $-828 \mathrm{~cm}^{-1}$ for $\mathrm{Cu}(\mathrm{II}) \mathrm{d}^{9}$ systems.

According to Hathaway [42], $K_{\|}=K_{\perp}=0.77$ for pure $\sigma$ bonding and $K_{\|}<K_{\perp}$ for in-plane bonding, while for out-of-plane bonding $K_{\|}>K_{\perp}$. It is seen that for complexes 1 and $4 K_{\|}>K_{\perp}$, indicating stronger out-of-plane $\pi$ bonding.

\section{Supplementary data}

Crystallographic data for structural analysis has been deposited with the Cambridge Crystallographic Data center, CCDC 231110 for compound $\left[\mathrm{Cu}_{2}(\mathrm{dptsc})_{2} \mathrm{Br}_{2}\right]$ (2) and CCDC 231109 for compound $\left[\mathrm{Cu}_{2}(\mathrm{dptsc})_{2}\left(\mathrm{~N}_{3}\right)_{2}\right]$ (3). Copies of this information may be obtained free of charge from The Director, CCDC, 12 Union Road, Cambridge, CB2 IEZ, UK (fax: +44-1223-336-033; e-mail: deposit@ccdc.cam.ac.uk or http://www.ccdc. cam.ac.uk).

\section{Acknowledgements}

The authors are thankful to the Regional Sophisticated Instrumentation Center, CDRI, Lucknow, India, for the elemental analysis and Sophisticated Instruments Facility, IISc Bangalore for NMR measurements.

\section{References}

[1] S.P.J. Albracht, Biochim. Biophys. Acta 111 (1993) 317.

[2] D.L. Klayman, J.P. Scovill, J.F. Bartosevich, J. Bruce, J. Med. Chem. 26 (1983) 35, and references therein.

[3] G.Z. Bahr, Allg. Chem. 268 (1952) 351A.
[4] G.Z. Bahr, Allg. Chem. 273 (1952) 325A.

[5] A.G. Quiroga, J.M. Perez, E.I. Montero, D.X. West, C. Alonso, C.N. Ranninger, J. Inorg. Biochem. 75 (1999) 293.

[6] F.A. French, E.J. Blanz Jr., J. Med. Chem. 9 (1996) 585.

[7] A.S. Dobek, D.L. Klayman, E.T. Dickson, J.P. Scovill, E.C. Tramont, Antimicrob. Agents Chemother. 18 (1980) 27.

[8] D.L. Klayman., A.J. Lin, J.W. McCall, J. Med. Chem. 34 (1991) 1422.

[9] C. Shipman Jr., H. Smith, J.C. Drach, D.L. Klayman, Antiviral Res. 6 (1986) 197.

[10] P.J. Blower, T.C. Castle, A.R. Cowley, J.R. Dilworth, P.S. Donnelly, E. Labisbal, F.E. Sowrey, S.J. Teat, M.J. Went, J. Chem. Soc., Dalton Trans. (2003) 4416.

[11] R.I. Maurer, P.J. Blower, J.R. Dilworth, C.A. Reynolds, Y. Zheng, G.E.D. Mullen, J. Med. Chem. 45 (2002) 1420 .

[12] P. Bindu, M.R.P. Kurup, T.R. Satyakeerthy, Polyhedron 18 (1999) 321.

[13] R.P. John, A. Sreekanth, M.R.P. Kurup, A. Usman, I.A. Razak, H.K. Fun, Spectrochim. Acta 59A (2003) 1349.

[14] M.R.P. Kurup, M. Joseph, Synth. React. Inorg. Met.-Org. Chem. 33 (2003) 1275

[15] A. Sreekanth, S. Sivakumar, M.R.P. Kurup, J. Mol. Struct. 655 (2003) 47.

[16] A. Sreekanth, U.L. Kala, C.R. Nayar, M.R.P. Kurup, Polyhedron 23 (2004) 41.

[17] A. Sreekanth, M.R.P. Kurup, Polyhedron 23 (2004) 969.

[18] C. Duan, B. Wu, T.C. Mak, J. Chem. Soc., Dalton Trans. (1996) 3485.

[19] C. Duan, X. You, T.C. Mak, Acta Crystallogr. C54 (1935) 1935.

[20] C. Duan, X. You, T.C. Mak, Acta Crystallogr. C54 (1935) 1937.

[21] J.K. Swearingen, D.X. West, Transition Met. Chem. 26 (2001) 252.

[22] J.K. Swearingen, W. Kaminsky, D.X. West, Transition Met. Chem. 27 (2002) 724.

[23] A. Usman, I.A. Razak, S. Chantrapromma, H.K. Fun, V. Philip, A. Sreekanth, M.R.P. Kurup, Acta Crystallogr. C58 (2002) 0652.

[24] V. Philip, V. Suni, M.R.P. Kurup, M. Nethaji, Polyhedron 23 (2004) 1225.

[25] Siemens, SMART and SAINT, Area Detector Control and Integration Software, Siemens Analytical X-ray Instruments Inc., Madison, Wisconsin, USA, 1996.

[26] G.M. Sheldrick, Acta Crystallogr. A46 (1990) 467.

[27] G.M. Sheldrick, shelXs-97 Program for the Solution of Crystal Structures, University of Göttingen, Göttingen, Germany, 1997.

[28] K. Brandenburg, H. Putz, DIAMOND version 3.0, Crystal Impact, GbR, Postfach 1251, D-53002 Bonn, Germany, 2004.

[29] B.N. Figgis, Introduction to Ligand Field, Wiley Interscience, New York, 1976

[30] V. Philip, V. Suni, M.R.P. Kurup, Acta Crystallogr. C60 (2004) 0856.

[31] B.S. Garg, M.R.P. Kurup, S.K. Jain, Y.K. Bhoon, Transition Met. Chem. 16 (1991) 111.

[32] M.J.M. Campbell, Coord. Chem. Rev. 15 (1975) 279.

[33] R. Mayer, in: M. Jansen (Ed.), Organosulfur Chemistry, Interscience, New York, 1967.

[34] R.P. John, A. Sreekanth, M.R.P. Kurup, S.M. Mobin, Polyhedron 21 (2002) 2515.

[35] B.J. Hathaway, A.A.G. Tomlinson, Coord. Chem. Rev. 5 (1970) 24. 
[36] M.A. Ali, M.T.H. Tarafdar, J. Inorg .Nucl .Chem. 39 (1977) 1785.

[37] K. Nakamoto, Infrared and Raman Spectra of Inorganic and Coordination Compounds, 5th ed., Wiley, New York, 1997.

[38] Y. Journaux, J. Sletten, O. Kahn, Inorg. Chem. 24 (1985) 4063.

[39] A. Sreekanth, M.R.P. Kurup, Polyhedron 22 (2003) 3321.
[40] D. Kivelson, R. Neiman, J. Chem. Phys. 35 (1961) 149.

[41] K.D. Karlin, J. Zubieta, Copper Coordination Chemistry Biological and Inorganic Perspectives, Adenine Press, New York, 1983.

[42] B.J. Hathaway, G. Wilkinson, R.D. Gillard, J.A. McCleverty (Eds.), Comprehensive Coordination Chemistry, Pergamon, Oxford, 1987. 